\title{
Dimensão ética da investigação científica
}

\section{Ethical dimension of scientific investigation}

\section{La dimensión ética de la investigación científica}

\begin{abstract}
Antônio Joaquim Severino*
Resumo: Após ressaltar a preocupação crescente com as questões éticas, relacionadas à pesquisa científica envolvendo sujeitos humanos, por parte de instâncias responsáveis pelo fomento da ciência no país, o texto discorre sobre as diversas perspectivas sob as quais se estabelecem as relações entre a ética e a produção do conhecimento, destacando a íntima vinculação da dimensão ética com a dimensão política, dada a exigência de afirmação da alteridade, da presença do outro, para que se possa falar da qualidade ética de qualquer ação humana. Conclui que as iniciativas com vistas à normalização dos procedimentos de investigação científica se legitimam como mediações importantes para se assegurar à prática científica o respeito à dignidade humana.
\end{abstract}

Palavras-chave: Ética. Pesquisa. Regulação.

\begin{abstract}
After emphasizing the growing concern about ethical issues related to scientific research involving human subjects by bodies responsible for the promotion of science in Brazil, this paper discusses the different perspectives under which relationships between ethics and production knowledge are established, highlighting the close connection of the ethical dimension to the political dimension, given the need for affirmation of otherness, for the presence of the other, so that one can discuss the ethical quality of any human action. It is concluded that initiatives aiming at standardizing procedures of scientific research are legitimated as important means to ensure respect for human dignity in the scientific practice.
\end{abstract}

Keywords: Ethics. Research. Regulation.

Resumen: Tras destacar la creciente preocupación por las cuestiones éticas relacionadas con la investigación científica en seres humanos por los organismos responsables de la promoción de ciencia en Brasil, en este trabajo se analizan las diferentes perspectivas en que se establecen las relaciones entre la ética y la producción de conocimiento, destacando la estrecha relación de la dimensión ética a la dimensión política, dada la necesidad de afirmación de la alteridad, de la presencia del otro, de modo que si puede discutir la calidad ética de toda acción humana. Se concluye que las iniciativas

* Professor do Programa de Pós-Graduação em Educação da Universidade Nove de Julho e da Faculdade de Educação da Universidade de São Paulo. E-mail: <ajsev@uol.com.br> 
encaminadas a la normalización de los procedimientos de la investigación científica se legitiman como medio importante para garantizar el respeto de la dignidad humana en la práctica científica.

Palabras clave: Ética. Investigación. Reglamento.

\section{Introdução}

A problemática da ética impregna capilarmente nossa existência cotidiana com a mesma intensidade que a problemática epistêmica; eis que todas as expressões concretas de nosso existir estão sempre inelutavelmente envolvidas com uma significação conceitual e com uma apreciação valorativa. Não há como escapar, tal situação é marca constitutiva da condição humana. Em tudo que fazemos, está sempre envolvido algum saber bem como alguma valoração. Isso decorre fundamentalmente da condição de entes dotados de uma dimensão de radical subjetividade, que nos coloca diante dos objetos de nossa experiência. Do ato mais simples ao mais complexo, um equacionamento subjetivo simultaneamente conceitual e valorativo perpassa sua realização concreta.

Não pode então ser diferente quando está em pauta a atividade científica, em todos os seus aspectos, momentos e suas modalidades. Daí a pertinência e oportunidade da iniciativa da Anped de promover, por ocasião de seus encontros oficiais, quando está em questão fazer balanços de sua produção científica, situação institucional e participação na vida mais ampla da sociedade brasileira, de gerar espaços para esta discussão.

Essa sensibilidade à problemática da ética se expressa em todos os espaços em que a vida acadêmica e científica se desenrola. Não se dá apenas na dimensão filosófica, sob inquietações solitárias de estudiosos isolados. Ganha ressonância nos mais variados lugares culturais e institucionais, produzindo repercussões e induzindo medidas que causam impacto na vida cotidiana das comunidades, pois o que está em jogo afeta todas as pessoas, sem exceção. Invade até as esferas do senso comum.

À guisa de exemplos, em nosso contexto, elenco algumas situações bem representativas. É o caso de uma iniciativa do CNPq que, ao longo de 2011, reagindo às frequentes ocorrências de fraude em publicações científicas, envolvendo inclusive pesquisadores apoiados por esse órgão, e preocupado com a necessidade de boas condutas nas pesquisas científicas e tecnológicas, instituiu uma Comissão Especial formada por cientistas brasileiros de grande experiência e liderança, com a missão de propor recomendações e diretrizes sobre o tema 
da ética e integridade na prática científica, seja em sua realização, seja em sua divulgação. A Comissão apresentou seu relatório final fazendo recomendações ao CNPq, propondo ações preventivas e educativas e ações de desestímulo a más condutas e até mesmo medidas punitivas. Propôs também que o órgão criasse uma Comissão Permanente de Integridade Científica para acompanhar e cuidar da prática científica no país.

Já em 2010, o Conselho Federal da OAB aprovou uma recomendação formal a todas as Instituições de Ensino Superior do país, propondo medidas concretas e eficazes visando coibir o plágio nas atividades acadêmicas. O que preocupa a $\mathrm{OAB}$ é a proliferação de trabalhos escolares feitos mediante a apropriação de produções alheias, sem a atribuição dos créditos devidos, caracterizando-se graves delitos. Tais ocorrências tornaram-se facilmente operacionalizáveis graças aos recursos da Internet e da informática. De acordo com a justificativa apresentada pelo relatório da $\mathrm{OAB}$ :

[...] a desonestidade moral e intelectual disseminou-se de tal forma que alguns alunos traduzem monografias inteiras de outros idiomas por ferramentas eletrônicas e intitulam-se autores dos trabalhos. Alguns estudantes chegam ao absurdo de comprar monografias de terceiros para colocar seu nome na autoria. (CONSELHO FEDERAL DA OAB, 2010, p. 2, grifo do autor).

Esta proposição foi assumida pela Capes, que a repassou a todos os Programas de Pós-Graduação do país, endossando-a integralmente e reforçando "a necessidade de combate ao plágio onde quer que este se manifeste" (CAPES, 2011, p. 2).

Essas iniciativas nascem da crescente ocorrência de práticas no âmbito acadêmico e científico que tem conturbado e ameaçado o ambiente de produção do conhecimento, tais como fabricação e invenção de dados, falsificação de resultados, plágios e autoplágios. Embora os processos denunciados sejam mais de natureza epistêmica, comprometendo a validade dos conhecimentos produzidos, a situação tem repercussão no plano ético, na medida em que traduz um relaxamento no compromisso do pesquisador com a fidedignidade de suas ações propriamente científicas.

A necessidade de se tomar medidas normativas e punitivas com relação a essas práticas consideradas como más condutas reflete um clima de insegurança com relação à postura dos pesquisadores e traz à baila o debate sobre os diversos aspectos que envolvem a dimensão ética na investigação científica.

Mas o exemplo mais representativo ainda é dado por iniciativas do Conselho Nacional de Saúde, responsável que é pelas atividades desenvolvidas no país na área médica, envolvendo assim a pesquisa científica do campo biológico e sanitário. Nessas situações, a questão ética no âmbito da investigação se agudiza 
e se coloca num maior grau de intensidade, por estar em pauta não apenas os procedimentos operacionais da pesquisa, mas a própria natureza de seu objeto. Trata-se particularmente do caso da pesquisa com seres humanos. Preocupação que surge, sobretudo, nas áreas das Ciências da Vida, mas que acaba se estendendo para todo o campo das Ciências Humanas.

Assim, em 1996, o referido Conselho lançara a "Resolução 196”, que traz diretrizes para o procedimento científico relacionado à investigação com sujeitos humanos, visando defender a integridade e a dignidade dos mesmos e assegurar que a pesquisa se desenvolva dentro de padrões éticos. Daí a exigência de que as instituições criem e mantenham seus Comitês de Ética e que todos os projetos de pesquisa envolvendo sujeitos humanos, antes de serem executados, sejam examinados e aprovados por eles, sob essa perspectiva ética.

Em dezembro de 2012, o Conselho Nacional de Saúde aprova uma nova versão de sua Resolução, agora sob o n. 466, fazendo uma revisão e atualização da Resolução 196, alegando atender as novas necessidades nas áreas tecnocientífica e ética. Trata-se de se manter atualizada com o debate concernente a essa questão ética.

Mas o complexo de dispositivos constantes desta Resolução tem suscitado muitas dúvidas e inquietações, particularmente entre os pesquisadores da área das Ciências Humanas. Em seminário preparatório a esta reunião da Anped, ocorrido em 07 de agosto do corrente, na Faculdade de Educação da Unicamp, Cynthia Sarti, falando da perspectiva da pesquisa antropológica, insistiu na necessidade de se distinguir pesquisa em seres humanos, que é a que ocorre nas Ciências Biomédicas, da pesquisa com seres humanos, que é a que ocorre nas Ciências Humanas. A ABA, Associação Brasileira de Antropologia, posicionou-se propondo, inclusive por meio de moção, que se elabore regulamentação específica para as pesquisas na esfera das Ciências Humanas. A ABA inclusive elaborou um código de ética próprio, o Código de Ética do Antropólogo. (CAPES, 2011, p. 3).

Estas breves referências são suficientes para se caracterizar a preocupação com a ética no âmbito da pesquisa científica em nosso contexto, particularmente no concernente às pesquisas envolvendo sujeitos humanos.

Tais iniciativas expressam a grave preocupação dos gestores e das instituições que cuidam de pesquisa com a qualidade ética da produção de conhecimento. As iniciativas destes exemplos são medidas que se situam no plano da normatividade positiva, estabelecendo, por assim dizer, códigos positivos de conduta para os pesquisadores, análogos aos Códigos de Ética que já existem estabelecidos para o exercício de quase todas as profissões.

Mas a questão que intriga é o fato da necessidade da criação e execução de normas, de forma quase que impositiva, para uma categoria de agentes, no caso 
os cientistas, cuja ação já pressupõe um nível de maturidade teórica, intelectual e cultural, que era de se supor, não necessitaria de determinações heterônomas para agir eticamente. Não deveriam ser necessários para o pesquisador, de modo aguçado para o intelectual pesquisador da educação, códigos positivos de ética profissional, por se tratar de referência heteronômica, já que é de se supor que ele se apoia numa ética fundada na autonomia, âmbito da legitimidade, tanto para assegurar seus próprios direitos como os direitos alheios.

Estou certo de que os colegas participantes desta mesa tratarão mais diretamente dos aspectos objetivos e concretos dessas iniciativas, problematizando diretamente o conteúdo das Resoluções do Conselho Nacional de Saúde, particularmente levando em conta a extensão de seus dispositivos aos casos de trabalhos investigativos do campo das Ciências Humanas. Assim, trarão elementos de ordem técnica e operacional na configuração de instrumentos reguladores para a condução da investigação científica na nossa área (como o uso da Plataforma Brasil), demonstrando em que medida determinados dispositivos dessas Resoluções são pertinentes ou não à prática científica na educação. Por isso mesmo, colocando-me na perspectiva da análise filosófica da questão da eticidade da conduta científica, propus-me então trazer alguns elementos sobre a natureza da eticidade humana e sua aplicação no caso específico do trabalho científico, com alguma especificação para o campo do conhecimento educacional.

\section{Três perspectivas éticas}

Começo lembrando que as questões éticas relacionadas ao comportamento humano se colocam de três perspectivas bem abrangentes, ou seja, as manifestações concernentes à perspectiva ética bem como os esforços para objetivá-las em normas positivas podem ser vistas desses três ângulos. Obviamente que, embora pareçam recortes distintos, são complementares e interligados entre si.

De um primeiro ponto de vista, podemos considerá-la em sua interface com o macrossocial, quando estão em pauta iniciativas que envolvem sociedades e estados. Nesse caso, estamos diante de tomadas de decisão e de práticas bem abrangentes, atingindo a toda a humanidade. Como exemplos, podemos tomar, além das guerras, situações como aquelas decorrentes do desenvolvimento e de aplicação de tecnologias que trazem ou podem trazer ameaças e danos para as sociedades humanas: os casos da utilização da energia nuclear, das armas químicas e biológicas, as pesquisas genéticas, as pesquisas ambientais. De forma que não predar ou poluir o ambiente natural, não maltratar os seres vivos tornam-se imperativos de valor ético, gerando cobrança por políticas públicas e de normas que coíbam tais ações e punam os infratores. Peter Singer elenca o cuidado com o ambiente e o tratamento atroz que é dado aos animais como dois graves desafios éticos da 
humanidade nos dias atuais. Esta é uma perspectiva em que a ética quase que se confunde com a política (SINGER, 2013, p. 12-13).

De um segundo ângulo, podemos considerar aquelas situações internas a grupos mais restritos, quando comportamentos de pessoas, isolada on coletivamente, ferem direitos e dignidade de outras pessoas ou grupos. Por exemplo, na manipulação desonesta de recursos comuns, na exploração dos mais fragilizados, na apropriação indébita de resultados e esforços de outros. Estamos aqui diante de situações mais objetivadas para as quais se criaram os códigos de éticas, que se empenham em descrever e traduzir, mediante normas de direito positivo, os procedimentos considerados inadequados, eticamente condenáveis e juridicamente penalizáveis. Embora mais localizadas em espaços menores, estas situações também envolvem o ético com o político, num círculo menos abrangente.

Mas o pesquisador se envolve ainda numa situação mais subjetivada, que depende mais intensamente de sua opção pessoal. É quando, com sua ação pessoal, possa estar ferindo direitos de terceiros, fraudando, no microcosmo de sua prática, determinados princípios éticos.

$\mathrm{Na}$ complexidade das situações reais, muitas vezes, todas estas situações se sobrepõem, de tal modo que os sujeitos as vivenciam simultaneamente, gerando implicações para suas opções. Mas, isoladas ou interligadas, em todas essas situações, está suposta uma esfera comum de significação do ético. É esse núcleo comum que define a eticidade das ações humanas. E para que se possa falar de uma referência ética, duas condições são postas como que a priori: a primeira, a presença da alteridade, a presença do outro; a segunda, o reconbecimento da dignidade da pessoa bumana. Assim, a ética envolve, de forma dialética, a presença de um eu frente a um outro. Ao mesmo tempo em que ela supõe um exercício radical da subjetividade mais íntima do próprio eu, ela supõe, com igual necessidade, a objetividade do outro que coloca em frente do eu a sua alteridade.

A necessária consideração da presença do outro, como condição de qualquer eticidade, far que os sentidos de ética e de política se entrelaçam intimamente. Não há como distinguir a qualidade ética de uma ação de sua qualidade política. A presença do outro em toda e qualquer circunstância da ação moral faz que toda ação envolva necessariamente as duas dimensões ao mesmo tempo, a ética e a política. Embora no discurso corrente, é comum usar separadamente os conceitos, toda ação humana, sob a perspectiva moral, é ético-política. O uso separado dos conceitos e dos termos visa apenas enfatizar o aspecto mais pessoal, quando se usa o termo ético, e o aspecto mais social, quando se usa o termo político.

Para clarear um pouco mais nossa questão, recorro às posições de Paul Ricoeur a respeito da ética, posições que considero fecundas para nos guiar nessa empreitada. De acordo com esse filósofo, a vivência ética recobre todo o espaço 
da existência histórica do homem, podendo ser expressa sob a seguinte formulação: "viver bem com e para os outros em instituições justas". São assim três momentos: o viver bem (o si mesmo), com e para os outros (dada a presença do outro), e em instituições justas (dada a necessidade de mediações objetivas para que o convívio entre as pessoas não seja sufocado pela violência).

Temos assim um primeiro momento em que prevalece a sensibilidade ética pessoal; um segundo momento em que prevalece a moralidade e um terceiro momento em que atua o julgamento, momento que Ricoeur designa como o momento da sabedoria prática. Na concepção de Ricoeur, estão presentes todos os elementos fundamentais da vivência ética ou da eticidade da existência humana: a sensibilidade do sujeito pessoal aos valores fundados na dignidade da condição de pessoa autônoma; a presença e a interação com o outro, o dado da alteridade, em que o outro se coloca como igualmente sujeito pessoal dotado de igual dignidade; a objetividade das circunstâncias da vida e a necessidade das instâncias institucionais como região e garantia das normas da convivência com outros, numa relação de justiça, e, finalmente, a necessidade e a capacidade de todos de formularem um juízo moral situado.

Cabe aqui um breve excurso semântico. Moral e ética são termos com origem etimológica análoga, ética procedendo do grego ethos e moral, do latino, mos, termos que significam originariamente costume, o agir costumeiro de uma comunidade, que têm uma valoração pelo que representa para essa comunidade. Mas esse primeiro sentido, que se refere ao modo concreto de uma forma de agir, ao que é, à dimensão do ser, agrega o sentido de um modo que deveria ser, acrescentando-se então a dimensão do dever-ser. Por isso, esses termos, seja quando usados como substantivos, seja quando usados como adjetivos, têm o significado estabelecido pelo seu contexto no discurso, já que, o mais das vezes, são usados como se sinônimos fossem. Em ambos os casos, estamos no círculo do agir e sempre referindo ao valor. Mas, a rigor, moral, como conceito, refere-se à relação das ações com os valores que a fundam, mas tais como consolidados num determinado grupo social, não exigindo uma justificativa desses valores que vá além da consagração coletiva em função dos interesses imediatos desse grupo. Estamos então no domínio do que é, de um fato social, sociologicamente apreensível. Já no caso da ética, refere-se a essa relação, mas sempre enquanto precedida de um investimento elucidativo dos fundamentos, das justificativas desses valores, independentemente de sua aprovação ou não por qualquer grupo. Estamos agora no domínio do que deve ser, um princípio axiológico, filosoficamente apreensível. Por isso, fala-se de ética em dois sentidos correlatos: de um lado, frisa-se a sensibilidade aos valores enquanto esses são justificados mediante uma busca reflexiva por parte dos sujeitos; de outro, convencionou-se chamar igualmente de ética a disciplina filosófica que busca elucidar esses fundamentos. 
Mas de onde vem o valor dos valores? Onde se funda a consciência moral? Se o homem é um ser histórico em construção, em devir, sem vinculação determinante à essência metafísica e à natureza física, naquilo que lhe é específico, onde ancorar a referência valorativa de sua consciência moral? $\mathrm{O}$ valor fundante dos valores que fundam a moralidade é aquele representado pela própria dignidade da pessoa humana, ou seja, os valores éticos fundam-se no valor da existência humana. É em função da qualidade desse existir, delineado pelas características que lhe são próprias, que se pode traçar o quadro da referência valorativa, para se definir o sentido do agir humano, individual ou coletivo. $\mathrm{Ou}$ seja, o próprio homem já é um valor em si, em suas condições de existência, sua radical historicidade, facticidade, corporeidade, incompletude e finitude, enfim, em sua contingência.

\section{Conclusão}

À luz destes elementos, podemos voltar aos problemas suscitados pelas tentativas de normalização da prática da pesquisa científica com sujeitos humanos.

A primeira observação a se fazer é que essas iniciativas e suas concretizações em códigos de ética profissional, em resoluções, integram as mediações de normalização positiva. Buscam criar referências legais, normativas, assinalando caminhos e procedimentos a serem seguidos pelos pesquisadores, até mesmo independentemente de suas convicções pessoais. Nesse sentido, a norma assume uma função mais jurídica do que ética. Obviamente, é de se esperar que quando as comunidades e os grupos criam esses documentos legais, eles tenham levado em conta a legitimidade dessas normas, ou seja, seu fundamento propriamente ético. Que tenham se pautado no compromisso de respeitar e proteger a dignidade dos sujeitos humanos envolvidos como objetos pesquisados. E como nos lembrou Ricoeur, essa mediação da moralidade, como regime de dispositivos e normas, positivamente impostos aos sujeitos, torna-se necessária "quando o desejo da vida boa se confronta com a violência sob todas suas formas" (RICOEUR, 1995, p. 132).

A favor desses instrumentos temos o testemunho da História, na medida em que tais documentos registram momentos significativos da luta da humanidade pela superação da barbárie, pelo reconhecimento dos direitos humanos, como temos os exemplos do Código de Nuremberg, de 1947, da Declaração Universal dos Direitos Humanos, de 1948, das Declarações de Helsinque (de 11964-200), da Declaração Universal sobre o Genoma Humano e os Direitos Humanos, de 1997; da Declaração Internacional sobre os Dados Genéticos Humanos, de 2013 e da Declaração Universal sobre Bioética e Direitos Humanos, de 2004, entre outros. Estes documentos, além da reafirmação de princípios, empenham-se 
igualmente em tecer considerações sobre os procedimentos concretos a serem seguidos quando estamos diante de práticas que interveem nos seres humanos.

Neste sentido, há que se reconhecer que as Resoluções 196 e 466, do Conselho Nacional de Saúde, representam, de fato, um passo significativo para o aprimoramento ético da pesquisa com seres humanos no Brasil e, em decorrência, representam igualmente um avanço na superação da barbárie.

As possíveis restrições que lhes podem ser feitas dizem respeito apenas a tecnicalidades e direcionamentos muito específicos, decorrentes do fato de se originarem no contexto muito peculiar da área médica. Mas reconhecido o pioneirismo da iniciativa, cabe às outras áreas traçarem trajetórias análogas, especificando para cada campo, o que devem prescrever no sentido de resguardar o alcance ético, ou seja, sair da mera normatividade imperativa legal para a legitimidade ética, explicitando os princípios que tomam como critérios. Entendo justificada a busca, no caso da comunidade científica da área geral das Ciências Humanas e da área particular das Ciências da Educação, de construção de seu projeto de normas e diretrizes éticas para o desenvolvimento da pesquisa científica. Nunca é demais repetir que a finalidade da educação é a humanização, a formação das pessoas humanas, e mais do que qualquer outra prática social, cabe a ela, nessa condição, investir na construção da autonomia das pessoas, respeitando e consolidando sua dignidade. Trata-se da própria construção do humano que não é dado como pronto e acabado, mas como um ser a ser construído, num processo permanente de um vir-a-ser, de um tornar-se humano. Pois ao emergir na superfície da biosfera, o homem é um ser totalmente imanente numa infraestrutura existencial que o prende por fortes amarras a uma série de a prioris existenciais, intrínsecos às pulsões da vida. Mas o processo de construção do humano, a humanização, não é um processo linear e harmonioso. Ele é conflituoso em decorrência da caminhada que tem de ser conjunta com o outro, que pode tornar-se uma ameaça para a própria identidade do eu em construção. É o conflito e o confronto das diferenças, ameaça contínua a toda identidade. A educação se situa no emaranhado seio desse conflito permanente.

O cuidado ético não é uma exigência apenas das intervenções do ensino e da extensão, mas igualmente da pesquisa. Trata-se então de não deixar que os comitês de ética se transformem em instâncias dominadas pelo cartorialismo burocrático das transações e nunca compactuar com os desmandos éticos na prática científica, lembrando-se sempre, com Heloani, que a ciência não é mesmo inocente (2013, p.4). Certamente cabe às Ciências Humanas demonstrar que toda bioética precisa ser, antes de tudo, uma antropoética (VON ZUBEN, 2006). 


\section{Referências}

CAPES. Orientações Capes: combate ao plágio. Brasília: Capes, 2011.

CONSELHO FEDERAL DA OAB. Comissão Nacional de Relações Institucionais. Proposição 2010.19.07379-01. Proposta de adoção de medidas para prevenção do plágio nas Instituições de Ensino e do comércio ilegal de monografias. Brasília: OAB, 2010.

FORPRED. Breve síntese do Seminário sobre Ética na Pesquisa em Educação promovido pelo Forpred Sudeste e PPG Educação/Unicamp. Campinas: Unicamp, 2013.

RICOEUR, P. Da metafísica à moral. Lisboa: Instituto Piaget, 1995.

SINGER, P. O dever de evitar o mal. Jornal da USP, São Paulo, v. 29, n. 1011, p. 12, 9-15 set. 2013.

VON ZUBEN, N. A. Bioética e tecnociências: a saga de Prometeu e a esperança paradoxal. Bauru: EDUSC, 2006.

Recebido em 10/10/2013

Aceito em 27/11/2013 